\title{
Evaluation of bovine chemerin (RARRES2) gene variation on beef cattle production traits ${ }^{1}$
}

\author{
Amanda K. Lindholm-Perry*, Larry A. Kuehn, Lea A. Rempel, Timothy P. L. Smith, Robert A. Cushman, \\ Tara G. McDaneld, Tommy L. Wheeler, Steven D. Shackelford, David A. King and Harvey C. Freetly
}

U.S. Meat Animal Research Center, Agricultural Research Service, United States Department of Agriculture, Clay Center, NE, USA ${ }^{2}$

Edited by:

Peter Dovc, University of Ljubljana,

Slovenia

Reviewed by:

Georgia Hadjipavlou, Agricutlural

Research Institute, Cyprus

Nora Lía Padola, Universidad Nacional

del Centro de la Provincia de Buenos

Aires, Argentina

*Correspondence:

Amanda K. Lindholm-Perry, U.S.

Meat Animal Research Center,

Agricultural Research Service, United

States Department of Agriculture,

P. O. Box 166, State Spur 18D, Clay

Center, NE 68933-0166, USA

e-mail: amanda.lindholm@

ars.usda.gov
A previous study in cattle based on $>48,000$ markers identified markers on chromosome 4 near the chemerin gene associated with average daily feed intake (ADFI) in steers $(P<0.008)$. Chemerin is an adipokine associated with obesity and metabolic syndrome in humans, representing a strong candidate gene potentially underlying the observed association. To evaluate whether the bovine chemerin gene is involved in feed intake, 16 markers within and around the gene were tested for association in the same resource population. Eleven were nominally significant for ADFI $(P<0.05)$ and two were significant after Bonferroni correction. Two and five SNP in this region were nominally significant for the related traits of average daily gain (ADG) and residual feed intake (RFI), respectively. All markers were evaluated for effects on meat quality and carcass phenotypes. Many of the markers associated with ADFI were associated with hot carcass weight (HCW), adjusted fat thickness (AFT), and marbling $(P<0.05)$. Marker alleles that were associated with lower ADFI were also associated with lower HCW, AFT, and marbling. Markers associated with ADFI were genotyped in a validation population of steers representing 14 breeds to determine predictive merit across populations. No consistent relationships for ADFI were detected. To determine whether cattle feed intake or growth phenotypes might be related to chemerin transcript abundance, the expression of chemerin was evaluated in adipose of 114 heifers that were siblings of the steers in the discovery population. Relative chemerin transcript abundance was not correlated with ADFI, ADG, or RFI, but associations with body condition score and yearling weight were observed. We conclude that variation in the chemerin gene may underlie observed association in the resource population, but that additional research is required to determine if this variation is widespread among breeds and to develop robust markers with predictive merit across breeds.

Keywords: average daily feed intake, beef cattle, BTA4, chemerin, feed intake, RARRES2

\section{INTRODUCTION}

Beef cattle producers could increase profitability by selecting for animals with increased feed efficiency, and genetic markers for animals with superior performance may facilitate selection. Average daily feed intake (ADFI), average daily gain (ADG) and residual feed intake (RFI) are all heritable traits $\left(h^{2}=0.24-0.57\right.$; Snelling et al., 2011), and can be altered with genetic selection. Considering the high cost of feed, even small changes in the amount of feed that cattle consume could equate to significant cost savings for producers.

In a previous genome-wide association study, four markers from the Illumina BovineSNP50 BeadChip mapping to bovine chromosome 4 (BTA4) between 113.3 and 113.6 Mb (UMD 3.1, genome assembly, Zimin et al., 2009) were nominally significant $(P \leq 0.008)$ for ADFI in a USMARC population of crossbred

\footnotetext{
${ }^{1}$ Mention of trade names or commercial products in this publication is solely for the purpose of providing specific information and does not imply recommendation or endorsement by the U.S. Department of Agriculture.

${ }^{2}$ USDA is an equal opportunity provider and employer.
}

steers (Snelling et al., 2011). The genes residing within this region included: 10 transfer RNA genes, three zinc finger genes involved in DNA and metal ion binding, KRAB-A domain containing 1 gene, the SCO-spondin homolog gene, ATPase, $H+$ transporting V0 subunit e2, leucine rich repeat containing 61 , chromosome 4 open reading frame, human C7orf29 (C4H7orf29) gene, and the chemerin (RARRES2) gene.

The adipokine, chemerin, also known as retinoic acid receptor responder 2 (RARRES2) or tazarotene-induced gene 2 protein (TIG2), is located within this region on BTA4 at $113.5 \mathrm{Mb}$, and is a cytokine produced by adipose tissue. Adipokines are involved in adipogenesis and inflammation responses via autocrine and paracrine actions (Coppack, 2001; Wisse, 2004; Rhee, 2011). Chemerin is highly expressed in adipocytes and its receptor (CMKLR1, also known as ChemR23) is expressed in immune cells and adipose tissue (Goralski et al., 2007). Circulating levels of chemerin have been associated with symptoms of metabolic syndrome in humans including; body mass index (BMI), fasting serum insulin, triglycerides, and HDL cholesterol (Bozaoglu et al., 2007, 2009), making it an 
attractive functional candidate gene for feed intake in beef cattle.

Other adipokines have previously been associated with feed intake and efficiency. Higher serum levels of leptin, an adipose derived hormone, have been correlated with higher dry matter intake (DMI), RFI and partial efficiency of growth in beef steers (Nkrumah et al., 2007). Circulating levels and mRNA expression levels of adiponectin have also been implicated in rats with a diet-induced obesity phenotype (Pérez-Encharri et al., 2005).

The purpose of this study was to evaluate polymorphisms within the adipokine, chemerin, as a source of phenotypic variation in ADFI in a U.S. Meat Animal Research Center (USMARC) population of cattle. In addition, we evaluated the relative gene expression levels of chemerin for association with cattle growth, weight, and feed intake.

\section{MATERIALS AND METHODS ANIMALS}

The USMARC Animal Care and Use Committee reviewed and approved all animal procedures. The procedures for handling the cattle complied with the Guide for the Care and Use of Agricultural Animals in Agricultural Research and Teaching (FASS, 1999).

\section{CROSSBRED STEERS (DISCOVERY POPULATION) AND HEIFERS (GENE EXPRESSION)}

The breeding scheme for the animals in the SNP discovery population $(n=1,066)$ and the heifers $(n=114)$ in this study has been described by Snelling et al. (2011). Briefly, purebred Angus, Hereford, Simmental, Limousin, Charolais, Gelbvieh, and Red Angus sires were bred to composite MARC III (1/4 Angus, 1/4 Hereford, 1/4 Pinzgauer, 1/4 Red Poll), Angus or Hereford cows by artificial insemination to produce $F_{1}$ animals, born in 1999, 2000, and 2001. Female $F_{1}$ and the 2001-born $F_{1}$ males (Angus, Hereford dams only) were kept for breeding, and mated in multiple-sire pastures to produce 2-, 3-, and 4-breed cross progeny designated $\mathrm{F}_{1}^{2}$. The $\mathrm{F}_{1}^{2}$ calves were born to 3-year-old and older dams in March through May from 2003 to 2007. Male calves were castrated within $24 \mathrm{~h}$ after birth. Calves were weaned in September at approximately 165 day of age (Snelling et al., 2011). Animals were screened and excluded for medical or health issues that may have affected either feed intake or gain phenotypes.

\section{VALIDATION POPULATION}

Validation animals $(n=406)$ were selected from progeny in the USMARC continuous Germplasm Evaluation Program (Kuehn et al., 2008). These animals were part of a breeding program to develop purebred cattle of each of the 14 breeds. In addition to the seven breeds mentioned above, this population also included Braunvieh, Shorthorn, Brahman, Maine Anjou, Santa Gertrudis, Salers, and Chi-Angus. Sires of each of these 14 breeds were mated to female descendents of cattle in the discovery population; none of the sires of the discovery population steers were sires of the validation animals. Approximately $60 \%$ of the validation animals were half-bloods sired by these seven new breeds and $40 \%$ were halfor three-quarter-bloods from the original seven breeds. Progeny were produced in three breeding seasons (Fall 2007, Spring 2008, and Fall 2008). Animals $(n=29)$ were removed from the analysis for chronic diagnoses (e.g., pneumonia, foot-rot, bloat).

\section{FEED EFFICIENCY PHENOTYPES}

Calves were trained on the test ration as described in Snelling et al. (2011). Briefly, beginning at $276 \pm 15$ day of age, individual feed intake measurements were acquired with Calan Broadbent Feeding Systems (American-Calan-Broadbent, Northwood, NH, USA). Animals were given feed at $0800 \mathrm{~h}$ and had ad libitum access to the feed. The dry matter mixed ration included $82.0 \%$ dry rolled corn, $10.6 \%$ ground alfalfa hay, $5.66 \%$ soybean meal, $1.25 \%$ limestone, $0.4 \%$ urea, $0.06 \%$ salt, $0.007 \%$ trace minerals, $0.008 \%$ Vitamins A, $\mathrm{D}$, and $\mathrm{E}$, and $0.015 \%$ Rumensin 80 . Feed refusals were obtained each week.

A description of feed efficiency phenotypes for $\mathrm{F}_{1}^{2}$ steers and heifers can be found in Snelling et al. (2011). The phenotypes were collected as follows: DMI was equal to cumulative DMI for the 140-day-feeding period. ADFI is the average daily DMI (DMI/140). Individual animal quadratic regressions were fitted for body weight on time, and gain was calculated as the difference of BW predicted at 140 day and the intercept (Rolfe et al., 2011). ADG is the calculation for gain divided by days on feed. Predicted DMI was computed from the regression of DMI on 140 day gain and day 70 mid-test $\mathrm{BW}^{75}$. RFI was calculated as the difference between observed DMI and predicted DMI (Snelling et al., 2011).

The steers used for the validation study were fed for either 84 or 148 day at $302 \pm 73$ day of age. Feed intake for those fed for 84 day was measured using an Insentec system (Marknesse, The Netherlands). Diets were similar to that used in the discovery population. DMI was equal to the total DMI consumed for either the 84 - or 148-day period and averaged to a daily basis (ADFI). A linear regression was used to predict BW in steers fed for 84 day and a quadratic equation was used to predict BW in steers fed for 140 day. ADG for both groups were calculated for the respective feeding periods as described in the discovery and heifer populations above.

\section{MEAT OUALITY AND CARCASS PHENOTYPES}

The $\mathrm{F}_{1}^{2}$ steers were serially harvested at a commercial processing plant as described by King et al. (2010) at $423 \pm 66$ day of age. USDA yield and quality grade data were provided by trained USMARC personnel after $36 \mathrm{~h}$ in the cooler at $0^{\circ} \mathrm{C}$. Wholesale ribs were obtained as described by King et al. (2010). A posterior section of the ribeye was frozen at 14-d postmortem and a $2.54-\mathrm{cm}$ thick steak was cut from the 11 th rib region. For slice shear force (SSF), steaks were thawed at $5^{\circ} \mathrm{C}$ for $24 \mathrm{~h}$, then cooked on a conveyor electric belt grill to a final internal temperature of $71^{\circ} \mathrm{C}$ as described by Wheeler et al. (2010). SSF was determined as described by Shackelford et al. (1999).

\section{CATTLE BODY CONDITION SCORE}

Body condition scores were obtained for $\mathrm{F}_{1}^{2}$ heifers. Body condition scoring is conducted on a 9-point scale to describe the overall fatness of an animal (NRC, 1996). A BCS of 1 describes an emaciated animal with a body fat percent of $\leq 3.77$. Five is an average BCS with body fat of $18.89 \%$ and a score of 9 describes a very fat animal with a body fat of $\geq 33.91 \%$ (NRC, 1996). Body condition scoring on $\mathrm{F}_{1}^{2}$ heifers was performed at $530 \pm 13$ day of age. 


\section{IDENTIFICATION OF SNP MARKERS IN CHEMERIN (RARRES2)}

Steers $(n=24)$ from the discovery population with extreme ADG or ADFI phenotypic and of different sire lines were selected for the SNP identification population. Twelve steers with low ADG or ADFI values and 12 steers with high ADG or ADFI phenotypes were chosen. Breeds were broadly represented in the animals with high and low phenotypes. Animals were screened and excluded for medical or health issues that may have affected either feed intake or gain phenotypes. Whole blood or buffy coats were collected from the steers for genomic DNA isolation.

Primer pairs to amplify the exonic and intronic boundaries of the chemerin gene from genomic DNA were designed using Primer $3^{3}$ (Rozen and Skaletsky, 2000). DNA sequences used as templates for primer design were obtained from the chromosome 4 Btau4.0 assembly. Oligonucleotide primers were synthesized by IDT (Integrated DNA Technologies, Coralville, IA, USA). PCR was performed in a DNA engine Dyad ${ }^{\circledR}$ peltier thermal cycler (BioRad, Hercules, CA, USA). PCR reactions included 0.25 U Hot Star Taq polymerase (Qiagen, Valencia, CA, USA); 1× supplied buffer; $1.5 \mathrm{mM} \mathrm{MgCl} 2 ; 80 \mu \mathrm{M}$ dNTPs; $0.33 \mu \mathrm{M}$ each primer; and $25 \mathrm{ng}$ genomic DNA in $12 \mu \mathrm{l}$ reactions. A portion of the PCR reaction $(3 \mu \mathrm{l})$ was electrophoresed on $2 \%$ agarose gels to determine quality of amplification. The remainder was treated with $0.1 \mathrm{U}$ exonuclease I (USB, Cleveland, OH, USA) and prepared for sequencing. Sequencing reactions were precipitated with 70\% isopropanol and sequenced on an ABI 3730 sequencer (Applied Biosystems, Foster City, CA, USA). Bases were called with Phred and assembled into contigs with Phrap. Polymorphisms were identified using Polyphred and assessed using Consed ${ }^{4}$.

\section{GENOTYPING ANALYSIS}

Multiplex assays for the Sequenom MASSARRAY ${ }^{\circledR}$ instrument were designed with the MASSARRAY ${ }^{\circledR}$ Assay Design 3.0 software (Sequenom, San Diego, CA, USA). Assays were designed to include 16 SNPs in and around chemerin from 113.54 to $113.62 \mathrm{Mb}$. Each amplification primer contained a 10-base tag to yield amplification products with different masses. Amplicon lengths were between 90 and $120 \mathrm{bp}$. Reaction conditions were performed as recommended by Sequenom. A total of 1,066 animals with DMI and ADG phenotypes and their sires $(n=71)$ were genotyped. The genotyping panel was redesigned to be a single multiplex assay for chemerin SNP for the validation and heifer populations. This panel included 12 SNP genotyped on the discovery population.

\section{STATISTICAL ANALYSES}

The program MTDFREML (Boldman et al., 1995) was used to analyze markers for significant associations. Twin animals and crossfostered animals were excluded from the analysis. The data were analyzed using an animal model that included the fixed effects of year and barn. Covariates of age and heterosis were also included. Calf and dam breed compositions were modeled with covariates for proportions Angus, Hereford, Simmental, Limousin, Charolais, Gelbvieh, Red Angus, and MARC III. Covariates for expected calf heterosis were computed from parental breed composition.

\footnotetext{
${ }^{3}$ http://frodo.wi.mit.edu

${ }^{4}$ http://www.phrap.org
}

SNP were fitted separately in the association model. Polygenic and breed effects were included to reduce the effects of family structure on breed- and family specific alleles (Kuehn et al., 2007; Goddard and Hayes, 2009). Variance components for polygenic effects and error were estimated using MTDFREML (Boldman et al., 1995). Nominal significance values were computed. Analyses of significant SNP in the validation population followed the same model definition.

\section{RNA ISOLATION AND GENE EXPRESSION}

Adipose tissue was collected from $\mathrm{F}_{1}^{2}$ heifers that were full or half siblings of the $\mathrm{F}_{1}^{2}$ steers in the discovery population at $360 \pm 40$ day of age. Evaluation of BCS occurred at approximately 5 months after the adipose tissue collection. After lidocaine injection, subcutaneous adipose tissue was surgically removed from 450 heifers from a small incision placed roughly $10 \mathrm{~cm}$ down from the tailhead and immediately stored at $-80^{\circ} \mathrm{C}$ until RNA extractions were performed. Total RNA was isolated from 50 to $100 \mathrm{mg}$ of adipose tissue from a random sampling of 150 heifers using the RNeasy Lipid Kit (Qiagen, Valencia, CA, USA) according to the manufacturer's instructions. Total RNA was quantified with a NanoDrop 8000 spectrophotometer (Wilmington, DE, USA). RNA $(2 \mu \mathrm{g})$ was reverse transcribed using $0.5 \mu \mathrm{g}$ ReadyMade random hexamer primers (Integrated DNA Technologies, Coralville, IA, USA) and M-MLV reverse transcriptase (Promega, Madison, WI, USA) according to the manufacturers protocol.

Primers used to amplify chemerin from cDNA were located in exons 2 and 3. Chemerin forward primer sequence was $5^{\prime}$-GGA GGAGTTCCACAAGCATC- $3^{\prime}$ and the reverse primer sequence was $5^{\prime}$-CCAGTCTTTCTTCCGACAGC-3'. The reference or internal control gene protein kinase $C$ inhibitor protein 1 , also known as tyrosine 3-monooxygenase/tryptophan 5-monooxygenase activation protein, gamma polypeptide (YWHAG) forward primer sequence was $5^{\prime}$-GCGAGACCCAGTATGAGAGC-3' and the reverse primer sequence was $5^{\prime}$-AAGGGCCAGGCCTAATC TAA-3'.

Real-time PCR was performed with $1 \times$ QuantiTect SYBR Green PCR Master Mix (Qiagen), $1 \mu \mathrm{l}$ of $50 \mathrm{ng} / \mu \mathrm{l} \mathrm{cDNA}$ template and $0.48 \mu \mathrm{M}$ each primer. The PCR reaction was performed at $95^{\circ} \mathrm{C}$ for $5 \mathrm{~min}$ followed by 41 cycles at $95^{\circ} \mathrm{C}$ for $10 \mathrm{~s}, 58^{\circ} \mathrm{C}$ for $20 \mathrm{~s}$, and $80^{\circ} \mathrm{C}$ for $1 \mathrm{~s}$ with a final melting curve from 78 to $95^{\circ} \mathrm{C}$ on a MJ PTC-200 with a Chromo-4 detector (MJ Research, Watertown, MA, USA). A pooled control sample was amplified with both primers sets on each plate. The threshold cycle $(\mathrm{Ct})$ for chemerin and $Y W H A G$ from each sample was determined and used to calculate the $\Delta \Delta \mathrm{Ct}$ using the reference pooled cDNA samples. The fold difference between samples was obtained using the $2^{-\Delta \Delta \mathrm{Ct}}$ method (Livak and Schmittgen, 2001).

\section{GENE EXPRESSION DATA ANALYSIS}

Gene expression data using the comparative $\mathrm{Ct}$ method $(\Delta \Delta \mathrm{Ct}$; Livak and Schmittgen, 2001) was analyzed for correlation with phenotypes using PROC CORR with SAS 9.2 (Cary, NC, USA) and MTDFREML. The $\Delta \Delta \mathrm{Ct}$ was chosen as the measure of expression because a reference pooled sample was used for normalization. The $\Delta \Delta \mathrm{Ct}$ units of expression displayed a normal distribution of values, low skewness $(-0.05)$ and low kurtosis $(-0.5)$. Gene 
expression data were analyzed for association with genotypes using MTDFREML. Fixed effects included birth year and date the tissue biopsy was performed. Covariates included gene expression plate, percent dam breed, breed percentage of each animal, and heterosis. Expression was also included as a covariate in phenotypic models for BCS and yearling weight adjusted to 365 day to detect the effect of higher expression of chemerin on each trait.

\section{LINKAGE DISEOUILIBRIUM ANALYSIS}

Linkage disequilibrium (LD; $r^{2}$ ) was defined for the 16 SNP on chromosome 4 using Haploview 4.0 software (Barrett et al., 2005) 5 . Blocks of LD were based on pairwise LD values. Haploview settings were as follows: the exclusion of animals with $>50 \%$ missing genotypes, ignoring pairwise comparisons of markers $>500 \mathrm{~kb}$ apart, the percentage of genotypes $\leq 50 \%$ and minimum minor allele frequency of 0.001 .

\section{RESULTS}

\section{CHEMERIN MARKER IDENTIFICATION AND ASSOCIATIONS} (DISCOVERY POPULATION)

To identify SNP in chemerin that may potentially be involved in cattle feed intake and growth variation, portions of the gene were sequenced in animals with extreme phenotypes. Four intronic SNP were identified (Table 1) and two of these were easily multiplexed into Sequenom iPLEX genotyping assays. Fourteen additional publicly available SNP located up- and down-stream of the chemerin gene from 113.54-113.62 Mb were also included in the genotyping assays (Table 2 ).

Of the 16 SNP genotyped in the discovery population, 11 were nominally significant for ADFI $(P \leq 0.05)$; of which, two were significant for ADG $(P \leq 0.03)$ and five were significant for RFI $(P \leq 0.04$; Table 3). One marker, 77244_529, located within intron 4 of the chemerin gene, was significant for all three phenotypes. After Bonferroni correction for multiple testing to account for testing 16 SNPs $(P$-value $=0.003$; alpha $=0.05 / 16)$, three of the SNP (BTB-00210449, 77244_529, and BFGL-NGS-19480) remained significant for ADFI $(P \leq 0.05$; Table 3$)$. These three markers are in low LD with each other $\left(r^{2} \leq 0.32\right.$; data not shown).

These markers were also analyzed for their effects on meat quality and carcass traits (Table 4). Several of these markers were significantly associated with adjusted fat thickness (AFT), hot carcass weight $(\mathrm{HCW})$ and marbling score (nominal $P \leq 0.05$ ), but none were associated with ribeye area (REA) or SSF.

\section{MARKER VALIDATION}

A validation of 12 of the markers tested in the discovery population (eight significantly associated with ADFI) was performed on a crossbred validation population of steers $(n=406)$ that included seven additional breeds of beef cattle (Table 5). Of the markers genotyped, none were validated with feed intake and gain in this population.

\section{CHEMERIN GENE EXPRESSION}

Chemerin gene expression $(\Delta \Delta \mathrm{Ct})$ was examined in adipose tissue collected from heifers related to the discovery population of

${ }^{5}$ http://www.broad.mit.edu/mpg/haploview/index.php

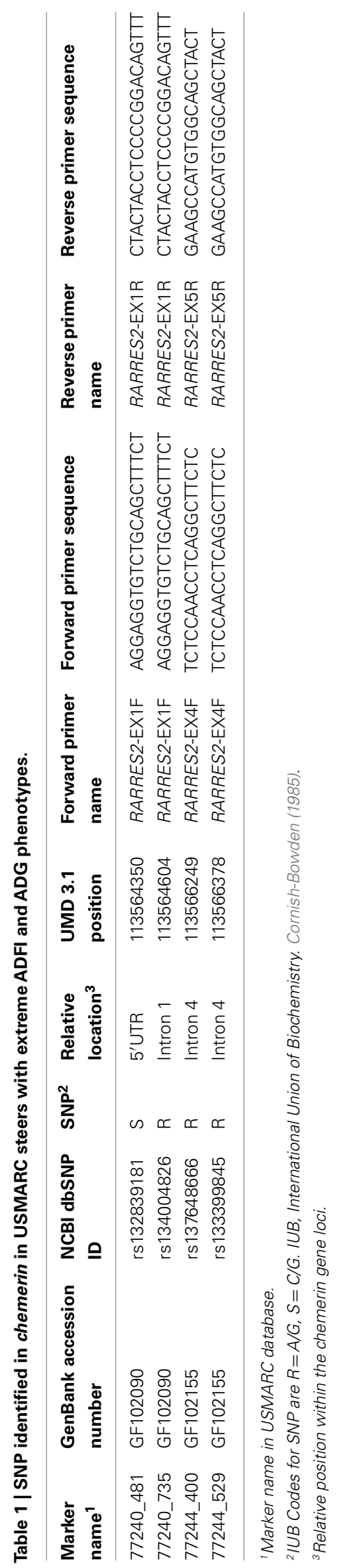


Table 2 | Markers on bovine chromosome 4 used to genotype the discovery population of steers.

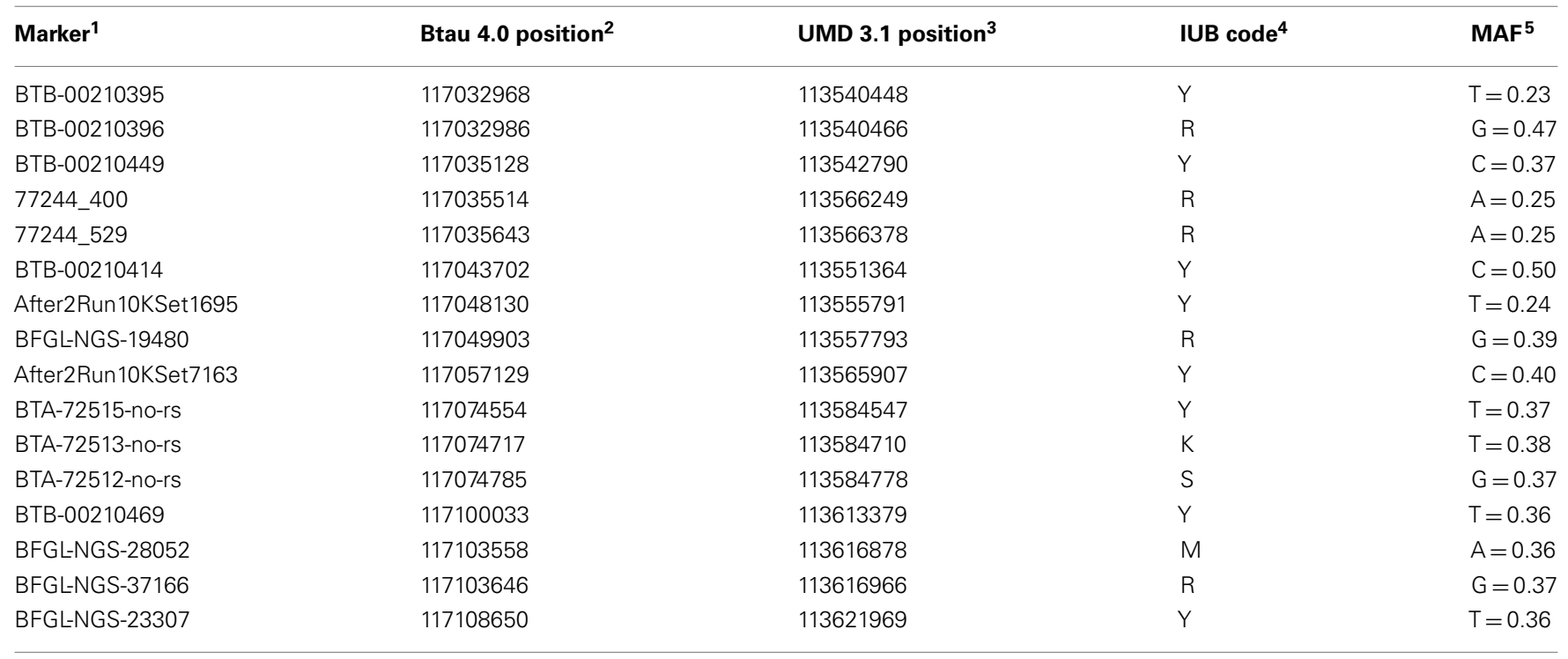

${ }^{1}$ Name of publicly available markers from the following references: Van Tassell et al. (2008), Bovine HapMap Consortium (2009), and Bovine Genome Sequencing and Analysis Consortium (2009).

${ }^{2}$ Position based on the Btau 4.0 Bovine genome assembly.

${ }^{3}$ Position based on the UMD 3.1 Bovine genome assembly.

${ }^{4} / U B$ Codes for $S N P$ are $K=G / T, M=A / C, R=A / G, S=C / G, Y=C / T$.

${ }^{5} \mathrm{MAF}$, minor allele frequency. MAF listed is from the discovery population of steers.

Table 3 | Marker associations and estimated effects for ADFI, ADG and RFI in the discovery population of steers.

\begin{tabular}{|c|c|c|c|c|c|c|c|}
\hline \multirow[t]{2}{*}{ Marker ${ }^{1}$} & \multirow[t]{2}{*}{ Allele } & \multicolumn{2}{|c|}{$\begin{array}{l}\text { Average daily feed } \\
\text { intake (kg/day) }\end{array}$} & \multicolumn{2}{|c|}{$\begin{array}{l}\text { Average daily gain } \\
\text { (kg/day) }\end{array}$} & \multicolumn{2}{|c|}{$\begin{array}{l}\text { Residual feed intake } \\
\text { (kg/day) }\end{array}$} \\
\hline & & Effect $^{2}$ & Nominal $P$ & Effect & Nominal $P$ & Effect & Nominal $P$ \\
\hline BTB-00210395 & $\mathrm{T}$ & -0.095 & 0.117 & -0.002 & 0.19 & $<0.0001$ & 0.34 \\
\hline BTB-00210396 & $\mathrm{G}$ & 0.027 & 0.533 & 0.012 & 0.888 & 0.027 & 1 \\
\hline BTB-00210449 & $\mathbf{T}$ & 0.18 & 0.001 & 0.02 & 0.078 & 0.066 & 0.067 \\
\hline 77244_529 & $\mathbf{G}$ & -0.198 & 0.003 & -0.03 & 0.031 & -0.11 & 0.011 \\
\hline BTB-00210414 & $\mathrm{T}$ & -0.052 & 0.306 & 0.018 & 0.086 & -0.057 & 0.077 \\
\hline After2Run10KSet1695 & $\mathrm{T}$ & 0.186 & 0.007 & 0.026 & 0.069 & 0.083 & 0.058 \\
\hline BFGL-NGS-19480 & G & 0.154 & 0.003 & 0.025 & 0.021 & 0.053 & 0.108 \\
\hline After2Run10KSet7163 & $\mathrm{T}$ & 0.072 & 0.166 & 0.001 & 1 & 0.042 & 0.206 \\
\hline BTA-72515-no-rs & $\mathrm{T}$ & -0.105 & 0.053 & -0.008 & 0.489 & -0.044 & 0.204 \\
\hline BFGL-NGS-28052 & $\mathrm{C}$ & -0.118 & 0.023 & -0.007 & 0.517 & -0.073 & 0.019 \\
\hline BFGL-NGS-37166 & G & 0.119 & 0.03 & 0.007 & 0.522 & 0.083 & 0.028 \\
\hline BFGL-NGS-23307 & $\mathrm{T}$ & 0.157 & 0.004 & 0.021 & 0.063 & 0.083 & 0.019 \\
\hline
\end{tabular}

${ }^{1}$ Name of publicly available markers from the following references: Van Tassell et al. (2008), Bovine HapMap Consortium (2009), and Bovine Genome Sequencing and Analysis Consortium (2009). Markers in bold are significant after Bonferroni correction for multiple testing. Correction for multiple tests based on the 16 markers genotyped in this study. A P-value of 0.003 was required for the marker to reach statistical significance $(\alpha=0.05 / 16$ markers $=0.003)$.

${ }^{2}$ The effect is based on the allele referenced in the Allele column. SE were between 0.043-0.068, 0.0089-0.014, and 0.028-0.044 for average daily feed intake, average daily gain and residual feed intake, respectively. 


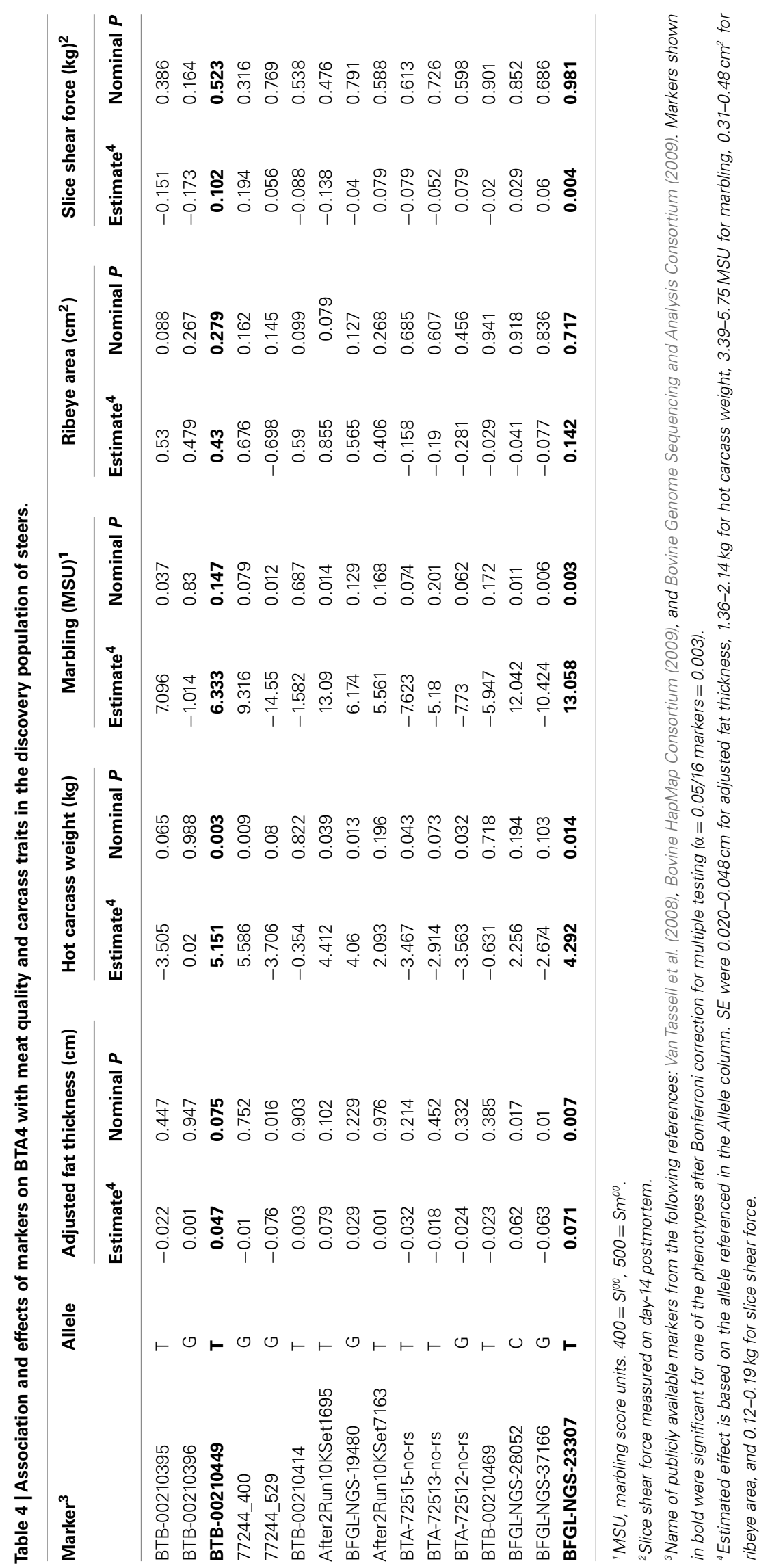


Table 5 | Association and effect of markers within and near chemerin on the validation population of steers.

\begin{tabular}{|c|c|c|c|c|c|c|c|}
\hline Marker $^{1}$ & Allele & \multicolumn{3}{|c|}{ Average daily feed intake (kg/day) } & \multicolumn{3}{|c|}{ Average daily gain (kg/day) } \\
\hline BTB-00210449 & $\mathrm{T}$ & 0.036 & 0.10 & 0.724 & 0.009 & 0.03 & 0.744 \\
\hline 77244_400 & G & -0.086 & 0.12 & 0.465 & -0.007 & 0.03 & 0.837 \\
\hline 77244_529 & $\mathrm{G}$ & 0.133 & 0.10 & 0.159 & 0.009 & 0.03 & 0.735 \\
\hline After2Run10KSet1695 & $\mathrm{T}$ & -0.100 & 0.10 & 0.294 & -0.007 & 0.03 & 0.795 \\
\hline BFGL-NGS-19480 & $\mathrm{G}$ & -0.035 & 0.07 & 0.597 & -0.009 & 0.02 & 0.614 \\
\hline After2Run10KSet7163 & $\mathrm{T}$ & -0.020 & 0.07 & 0.763 & 0.005 & 0.02 & 0.783 \\
\hline BTA-72515-no-rs & $\mathrm{T}$ & 0.146 & 0.07 & 0.050 & 0.025 & 0.02 & 0.222 \\
\hline BTA-72512-no-rs & $\mathrm{G}$ & 0.104 & 0.07 & 0.137 & 0.031 & 0.02 & 0.109 \\
\hline BTB-00210469 & $\mathrm{T}$ & 0.042 & 0.06 & 0.519 & 0.015 & 0.02 & 0.403 \\
\hline
\end{tabular}

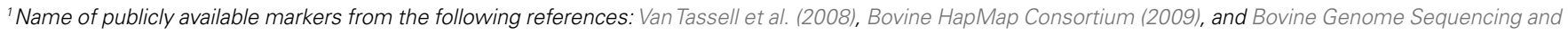
Analysis Consortium (2009).

${ }^{2}$ Estimated effect is based on the allele referenced in the Allele column.

Table 6 | Correlation coefficients for heifer phenotypes.

\begin{tabular}{|c|c|c|c|c|c|}
\hline & ADFI (kg/d) & RFI (kg/d) & $\Delta \Delta \mathrm{Ct}^{1}$ (Chemerin) & $\mathrm{BCS}^{2}$ & AYWt \\
\hline ADG & $0.42(<0.0001)$ & $-0.050(0.59)$ & $0.061(0.51)$ & $0.192(0.040)$ & $0.23(0.15)$ \\
\hline ADFI & & $0.53(<0.0001)$ & $0.14(0.13)$ & $0.31(0.0007)$ & $0.58(<0.0001)$ \\
\hline$\Delta \Delta \mathrm{Ct}$ & & & & $0.29(0.0015)$ & $0.20(0.033)$ \\
\hline $\mathrm{BCS}$ & & & & & $0.27(0.0038)$ \\
\hline
\end{tabular}

$A D F I$, average daily feed intake; RFI, residual feed intake; $\Delta \Delta C t$, comparative Ct method; BCS, body condition score; AYWt, 365 day adjusted yearling weight; $A D G$, average daily gain.

${ }^{1} \Delta \Delta$ Ct values for chemerin.

${ }^{2} B C S$ measured on a 9-point scale 5 months after adipose tissue for gene expression was collected.

steers (Table 6). Chemerin gene expression was correlated with BCS $(r=0.29 ; P=0.0015)$ and 365 day adjusted yearling weight $(r=0.20 ; P=0.03$; Table 6). There was slight, but not significant $(P \leq 0.16)$, correlation between chemerin gene expression and DMI and RFI ( $r=0.14$ and 0.13 , respectively; Table 6). We also analyzed gene expression with BCS using the statistical analysis program MTDFREML. The estimated effect of expression on BCS was 1 unit of $\Delta \Delta \mathrm{Ct}$ per 0.142 units increase in BCS $(P=0.004)$.

Chemerin gene expression and BCS were also evaluated for association with the markers located within and surrounding chemerin (data not shown). None of the markers were significant for chemerin gene expression or BCS.

\section{DISCUSSION}

Several markers on the Illumina BovineSNP50 BeadChip located near the chemerin gene on BTA4 were previously found to be associated with ADFI $(P=0.001-0.008)$ in the discovery population of steers (Snelling et al., 2011). In this study, we have further investigated chemerin SNP and gene expression as a source of feed intake phenotypic variation. These are the first studies that we are aware of associating genetic markers in and near the chemerin gene with feed intake variation in animals. The SNP presented in this study, along with those in this region on the BeadChip, may be useful for genetic selection of animals with superior phenotypes in multiple breeds of beef cattle. Moreover, we showed that variation in body condition score (BCS), a measure similar to BMI in humans, was positively correlated with chemerin gene expression.

The genetic markers analyzed in the discovery steer population in this study were most significantly associated with ADFI. Many of these markers were also associated with the related traits of ADG and/or RFI $(P$, nominal $\leq 0.05)$. Even though ADG and RFI associations were only nominally significant, their effects were in the expected direction (alleles with higher ADFI effects had higher ADG and RFI effects). In general, alleles that are associated with higher feed intakes, when also nominally significant for other traits, produced greater HCW and greater fat deposition. However, ribeye area and tenderness were not affected suggesting that the ribeye, and possibly other lean muscles, were not affected by the increased fat deposition. 
One marker, 77244_529, was nominally associated with ADFI, ADG, and RFI in our discovery population. An animal with the $G$ allele at this marker would be predicted to have a reduced feed consumption of $27.9 \mathrm{~kg}$ over a 140 -day-feeding period, which would be a significant cost savings at the feedlot. However, feed intake is a complex trait and since multiple genetic and environmental factors contribute to an animal's consumption of feed, these effects are not likely to be realized to this extent in different populations with this marker. Moreover, this marker was not significant in our validation population, suggesting a population specific association. Our genetic marker data indicated that the variation in the chemerin gene may be responsible for some of the observed ADFI variation in our discovery population; however, the lack of validation of these markers suggested that they may not be particularly robust across breeds and populations.

Additional studies within this region may be necessary to identify markers that are more useful across cattle populations. There is recent evidence that the gene expression of replication inhibitor 1 (Repin1) may be involved in metabolic disorder in rats (Bahr et al., 2011). A strain of rats (BB.4W) that develop obesity, dyslipidemia, impaired glucose tolerance, hyperinsulinemia, and hyperleptinemia displayed lower relative transcript abundance of Repin1 in adipose tissue. In cattle, REPIN1 is located within close proximity of the chemerin gene suggesting that studies to evaluate whether REPIN1 expression plays a role in cattle feed intake are warranted.

We performed SNP association analysis on heifers $(n=114)$ related to the discovery steer population and detected a few markers that were approaching significance with ADFI and RFI $(P \leq 0.1$; data not shown). This analysis was likely under-powered due to the limited number of heifers. However, these associations, the associations from the related discovery population of steers, and the half to partial sibling relationships between these two groups of animals provided support for the use of the heifer adipose tissue as an appropriate source to evaluate chemerin gene expression.

We found that chemerin gene expression in the adipose tissue of heifers was correlated to their BCS and yearling weight. A previous

\section{REFERENCES}

Bahr, J., Klöting, N., Klöting, I., and Follak, N. (2011). Gene expression profiling supports the role of Repin 1 in the pathophysiology of metabolic syndrome. Endocrine 40, 310-314.

Barrett, J. C., Fry, B., Maller, J., and Daly, M. J. (2005). Haploview: analysis and visualization of LD and haplotype maps. Bioinformatics 21, 263-265.

Boldman, K. G., Kriese, L. A., Van Vleck, L. D., Van Tassel, C. P., and Kachman, S. D. (1995). A Manual for the use of MTDFREML. A set of Programs to Obtain Estimates of Variance and Covariances (Draft). Lincoln: USDA, ARS.

Bovine Genome Sequencing, and Analysis Consortium. (2009). The genome sequence of taurine cattle: a window to ruminant biology and evolution. Science 324, 522-528.
Bovine HapMap Consortium. (2009). Genome-wide survey of SNP variation uncovers the genetic structure of cattle breeds. Science 324, 528-532.

Bozaoglu, K., Bolton, K., McMillan, J., Zimmet, P., Jowett, J., Collier, G., Walder, K., and Segal, D. (2007). Chemerin is a novel adipokine associated with obesity and metabolic syndrome. Endocrinology 148, 4687-4694.

Bozaoglu, K., Segal, D., Shields, K. A., Cummings, N., Curran, J. E., Comuzzie, A. G., Mahaney, M. C., Bainwater, D. L., VandeBerg, J. L., MacCluer, J. W., Collier, G., Blangero, J., Walder, K., and Jowett, J. B. M. (2009). Chemerin is associated with metabolic syndrome phenotypes in a Mexican-American population. J. Clin. Endocrinol. Metab. 94, 3085-3088.

study has shown a relationship between chemerin expression, adipogenesis and leptin (Goralski et al., 2007). RNA transcripts for chemerin and its receptor were found to be highly expressed in mouse white adipose tissue, which is responsible for energy storage (Goralski et al., 2007). This study also showed that chemerin was expressed at higher levels in differentiated adipocytes and chemerin, and its receptor, appeared to be necessary for adipocyte differentiation. In a post-differentiation chemerin knockdown experiment, performed in an adipocyte cell culture model, leptin gene expression was reduced (Goralski et al., 2007). These data provide evidence for a potential role of chemerin in cattle feed intake, as its effects on circulating leptin would alter appetite. In addition, a relationship between adipogenesis and chemerin expression may account for a portion of the variation in cattle BCS. Both adipogenesis and an effect on the leptin appetite pathway could affect an animal's feed intake phenotype and its overall level of body fat.

In summary, we have detected several polymorphisms within a region on bovine chromosome 4 , which includes the chemerin gene, that were significantly associated with feed intake in a discovery population of cattle. In general, the alleles that were associated with higher feed intakes were associated with higher HCW, AFT, and marbling, but no association with REA and tenderness was detected; thus, fat accretion may be responsible for the increase in HCW. However, we were not able to validate these associations in another population of cattle. Chemerin gene expression in the adipose tissue of heifers was greater in animals with greater BCS and yearling weights supporting data from human and mouse studies that indicate a relationship between chemerin and fat deposition.

\section{ACKNOWLEDGMENTS}

The authors appreciate the excellent technical assistance provided by Linda Flathman and Kris Simmerman. We also thank Donna Griess for manuscript preparation, and the USMARC cattle operations employees for animal care and management.

Coppack, S. W. (2001). Proinflammatory cytokines and adipose tissue. Proc. Nutr. Soc. 60, 349-356.

Cornish-Bowden, A. (1985). Nomenclature for incompletely specified bases in nucleic acid sequences: recommendations 1984. Nucleic Acids Res. 13, 3021-3030.

FASS. (1999). Guide for Care and Use of Agricultural Animals in Agricultural Research and Teaching, 1st Edn. Savoy: Fed Animal Science Society.

Goddard, M. E., and Hayes, B. J. (2009). Mapping genes for complex traits in domestic animals and their use in breeding programs. Nat. Rev. Genet. 92, 381-391.

Goralski, K. B., McCarthy, T. C., Hanniman, E. A., Zabel, B. A. Butcher, E. C., Parlee, S. D., Muruganandan, S., and Sinal, C. J. (2007). Chemerin, a novel adipokine that regulates adipogenesis and adipocyte metabolism. J. Biol. Chem. 282, 28175-28188.

King, D. A., Shackelford, S. D., Kuehn, L. A., Kemp, C. M., Rodriguez, A. B., Thallman, R. M., and Wheeler, T. L. (2010). Contribution of genetic influences to animal-to-animal variation in myoglobin content and beef lean color stability. J. Anim. Sci. 88, 1160-1167.

Kuehn, L. A., Keele, J. W., and Thallman, R. M. (2008). "Estimation of current breed differences in multibreed genetic evaluations using quantitative and molecular approaches," in Beef Improvement Federation: 9th Genetic Prediction Workshop. Prediction of Genetic Merit of Animals for Selection, Kansas City, 49-60.

Kuehn, L. A., Rohrer, G. A., Nonneman, D. J., Thallman, R. M., and Leymaster, K. A. (2007). Detection of 
single nucleotide polymorphisms associated with ultrasonic backfat depth in a segregating Meishan $\times$ White Composite population. J. Anim. Sci. 85, 1111-1119.

Livak, K. J., and Schmittgen, T. D. (2001). Analysis of relative gene expression data using real-time quantitative PCR and the $2^{-\Delta \Delta C T}$ Method. Methods 25, 402-408.

Nkrumah, J. D., Keisler, D. H., Crews, D. H. Jr., Basarab, J. A., Wang, Z., Li, C., Price, M. A., Okine, E. K., and Moore, S. S. (2007). Genetic and phenotypic relationships of serum leptin concentration with performance, efficiency of gain, and carcass merit of feedlot cattle. J. Anim. Sci. 85, 2147-2155.

NRC. (1996). Nutrient Requirements of Beef Cattle, 7th Rev. Edn., Washington, DC: National Academic Press.

Pérez-Encharri, N., Pérez-Matute, P., Martínez, J. A., Marti, A., and Moreno-Aliaga, M. J. (2005). Serum and gene expression levels of leptin and adiponectin in rats susceptible or resistant to diet-induced obeity. J. Physiol. Biochem. 61, 333-342.

Rhee, E.-J. (2011). Chemerin: a novel link between inflammation and atherosclerosis? Diabetes Metab. J. 35, 216-218.
Rolfe, K. M., Snelling, W. M., Nielsen, M. K., Freetly, H. C., Ferrell, C. L., and Jenkins, T. G. (2011). Genetic and phenotypic parameter estimates for feed intake and other traits in growing beef cattle and opportunities for selection. J. Anim. Sci. 89, 3452-3459.

Rozen, S., and Skaletsky, H. J. (2000). "Primer3 on the WWW for general users and for biologist programmers," in Bioinformatics Methods and Protocols: Methods in Molecular Biology, ed. S. Krawetz and S. Misener (Totowa: Human Press), 365-386.

Shackelford, S. D., Wheeler, T. L., and Koohmaraie, M. (1999). Evaluation of slice shear force as an objective method of assessing beef longissimus tenderness. J. Anim. Sci. 77, 2693-2699.

Snelling, W. M., Allan, M. F., Keele, J. W., Kuehn, L. A., Thallman, R. M., Bennett, G. L., Ferrell, C. L., Jenkins, T. G., Freetly, H. C., Nielsen, M. K., and Rolfe, K. M. (2011). Partialgenome evaluation of postweaning feed intake and efficiency of crossbred beef cattle. J. Anim. Sci. 89, 1731-1741.

Van Tassell, C. P., Smith, T. P., Matukumalli, L. K., Taylor, J. F., Schnabel, R.
D., Lawley, C. T., Haudenschild, C. D., Moore, S. S., Warren, W. C., and Sonstegard, T. S. (2008). SNP discovery and allele frequency estimation by deep sequencing of reduced representation libraries. Nat. Methods 5, 247-252.

Wheeler, T. L., Cundiff, L. V., Shackelford, S. D., and Koohmaraie, M. (2010). Characterization of biological types of cattle (Cycle VIII): carcass, yield, and longissimus palatability traits. J. Anim. Sci. 88, 3070-3083.

Wisse, B. E. (2004). The inflammatory syndrome: the role of adipose tissue cytokines in metabolic disorders linked to obesity. J. Am. Soc. Nephrol. 15, 2792-2800.

Zimin, A. V., Delcher, A. L., Florea, L., Kelley, D. R., Schatz, M C., Puiu, D., Hanrahan, F., Pertea, G., Van Tassell, C. P., Sonstegard, T. S., Marcais, G., Roberts, M. Subramanian, P., Yorke, J. A., and Salzberg, S. L. (2009). A whole genome assembly of the domestic cow, Bos Taurus. Genome Biol. 10, R42.

Conflict of Interest Statement: Mention of trade name proprietary product or specified equipment does not constitute a guarantee or warranty by the USDA and does not imply approval to the exclusion of other products that may be suitable. USDA is an equal opportunity provider and employer.

Received: 15 November 2011; accepted: 29 February 2012; published online: 29 March 2012.

Citation: Lindholm-Perry AK, Kuehn LA, Rempel LA, Smith TPL, Cushman RA, McDaneld TG, Wheeler TL, Shackelford SD, King DA and Freetly HC (2012) Evaluation of bovine chemerin (RARRES2) gene variation on beef cattle production traits. Front. Gene. 3:39. doi: 10.3389/fgene.2012.00039

This article was submitted to Frontiers in Livestock Genomics, a specialty of Frontiers in Genetics.

Copyright (C) 2012 Lindholm-Perry, Kuehn, Rempel, Smith, Cushman, McDaneld, Wheeler, Shackelford, King and Freetly. This is an open-access article distributed under the terms of the Creative Commons Attribution Non Commercial License, which permits non-commercial use, distribution, and reproduction in other forums, provided the original authors and source are credited. 